\title{
SISTEM TRANSMISI DATA GULA DARAH BERBASIS ARDUINO
}

\author{
Ika Puspita \\ Program Studi Teknik Elektro, Fakultas Teknik, Universitas Fajar, Makassar \\ Jl. Prof. Abdurrahman Basalamah No. 101 Makassar \\ email : ikapuspita_elektro@yahoo.com
}

\begin{abstract}
This study aims to design an interface that connects blood sugar measurement devices with mobile phones and design a database system and visual display for monitoring blood sugar levels in the patient's body. This monitoring system integrates several tools used to transmit data measuring the results of blood sugar. On the patient side there is a glucometer, arduino, along with bluetooth and android-based mobile phones that will be used to send measurement data to the web server so that it can be accessed by doctors to monitor the development of the patient's health condition. Based on observations obtained an error value of $23.33 \%$ for 60 seconds of observations, an error of $32 \%$ for observations for 90 seconds, and an error of $31.11 \%$ for 120 seconds of observations.
\end{abstract}

Keywords : Bluetooth, Diabetes, Glucometer, Arduino.

Abstrak - Penelitian ini bertujuan merancang sebuah interface yang menghubungkan antara alat ukur gula darah dengan handphone serta merancang sistem basis data dan visual display untuk monitoring kadar gula darah pada tubuh pasien. Sistem monitoring ini mengintegrasikan beberapa alat yang digunakan untuk mentransmisikan data hasil pengukuran gula darah. Pada sisi pasien terdapat glucometer, arduino, beserta bluetooth dan handphone berbasis android yang akan digunakan untuk mengirim data hasil pengukuran ke web server sehingga dapat di akses oleh dokter untuk memantau perkembangan kondisi kesehatan pasien. Berdasarkan hasil pengamatan diperoleh nilai error sebesar $23,33 \%$ untuk hasil pengamatan selama 60 detik, error sebesar 32\% untuk hasil pengamatan selama 90 detik, dan error sebesar $31,11 \%$ untuk hasil pengamatan selama 120 detik.

Kata Kunci : Bluetooth, Diabetes, Glucometer, Arduino.

\section{PENDAHULUAN}

Teknologi informasi yang berbasis wireless sudah menjadi suatu keharusan dalam berbagai aspek kehidupan. Dengan ini, informasi dapat disajikan secara real time, cepat dan tentunya sangat mudah diakses oleh pihak-pihak yang berkepentingan. Dalam bidang kesehatan, ICT sangat diperlukan untuk melakukan monitoring terhadap kondisi kesehatan pasien khususnya yang berkaitan dengan penyakit diabetes.[1] Diabetes adalah penyakit metabolik yang dapat mempengaruhi hampir setiap sistem organ dalam tubuh. Jumlah penderita Diabetes melitus di Indonesia sekitar 17 juta orang atau 8,6 persen dari jumlah penduduk dan menduduki urutan terbesar ke-4 setelah India, Cina, dan Amerika Serikat (AS). Penyakit diabetes dapat dideteksi lebih awal dengan melakukan pemeriksaan darah secara teratur. [2]

Berdasarkan hasil survei (diskusi) dengan dokter bahwa pasien penderita diabetes harus sering dipantau tingkat gula darahnya secara reguler dalam sehari. Misalnya, pada pasien dengan tingkat gula darah lebih dari
$300 \mathrm{mg} / \mathrm{dl}$ dan terjadi penurunan kesadaran atau sesak harus dilakukan pengukuran setidaknya 3 jam sehari. Begitupula dengan kasus ibu hamil yang kadar gula darahnya sangat rendah atau sangat tinggi, dimana kadar gula darahnya harus dipantau secara reguler dalam sehari untuk menjaga kesehatan ibu dan cabang bayi dalam kandungan.

Saat ini pembacaan hasil pengukuran gula darah masih dilakukan secara manual dicatat pada sebuah log book yang selanjutnya akan diinput secara manual pula pada database pasien di komputer. Selain itu, database pasien belum bisa dipantau secara mobile oleh dokter sehingga pasien pada sebuah rumah sakit harus menunggu dulu hingga dokter tiba di rumah sakit untuk mengetahui tindakan medis selanjutnya. Sehingga dibutuhkan sistem transmisi data gula darah agar kondisi pasien dapat dipantau.

\section{PENELITIAN YANG TERKAIT}

\subsection{Glukosa}

Glukosa merupakan kelompok senyawa karbohidrat sederhana atau monosakarida. Di alam, glukosa terdapat dalam buah-buahan dan madu lebah. Glukosa berfungsi sebagai sumber energi untuk sel-sel otak, sel saraf, dan sel darah merah. Darah manusia normal mengandung glukosa dalam jumlah atau konsentrasi yang tetap, yaitu antara 70$100 \mathrm{mg}$ tiap $100 \mathrm{ml}$ darah. Pada orang yang menderita diabetes melitus, jumlah glukosa darah lebih besar dari $130 \mathrm{mg} / 100 \mathrm{ml}$ darah.[3]

Agar dapat berfungsi secara optimal, tubuh hendaknya dapat mempertahankan konsentrasi darah gula dalam batas-batas tertentu, yaitu $70-120 \mathrm{mg} / \mathrm{ml}$ dalam keadaan puasa. Bila gula darah naik di atas $130 \mathrm{mg} / 100 \mathrm{ml}$, gula akan dikeluarkan melalui urine. Sebaliknya bila gula darah turun hingga 40-50 mg/ml, pasien akan merasa gugup, pusing, lemas dan lapar. Gula darah yang terlalu tinggi disebut hiperglikemia dan bila gula darah terlalu rendah disebut hipoglikemia.[4]

\subsection{Bluetooth}

Bluetooth adalah nama produk industri komunikasi yang diperuntukkan bagi Personal Area Network (PAN). Gelombang radio yang digunakan adalah short range radio frequency tanpa lisensi sehingga untuk menggunakan teknologi bluetooth tidak dibutuhkan lisensi khusus untuk pemanfaatan jalur frekuensi. Jarak jangkau dari gelombang radio hanya mencapai 1 meter sampai 100 meter karena itu disebut dengan short-range. Standar dari bluetooth dibuat oleh Bluetooth Special Interest Group. Bluetooth merupakan sebuah teknologi komunikasi nirkabel (tanpa kabel) yang beroperasi pada frekuensi 2.5 Ghz. Komunikasi pada bluetooth sangat erat kaitannya 
e-ISSN : 2715-5064

dengan jaringan piconet. Sebuah piconet paling sederhana terdiri dari dua buah peralatan bluetooth dimana yang satu menginisialisasi koneksi sebagai master (pengirim), sedangkan perangkat lain yang menerima dinamakan sebagai slave. Untuk dapat bertukar data melalui bluetooth, maka kedua perangkat yang akan dihubungkan harus melakukan pairing terlebih dulu.[5]

\subsection{Arduino Mega2560}

Arduino Mega 2560 adalah papan mikrokontroler berbasiskan Atmega 2560 (datasheet Atmega 2560). Arduino Mega 2560 memiliki 54 pin digital input/output, dimana 15 pin dapat digunakan sebagai output PWM, 16 pin sebagai input analog, dan 4 pin sebagai UART (port serial hardware), $16 \mathrm{MHz}$ kristal osilator, koneksi USB, jack power, header ICSP, dan tombol reset. Semua ini yang diperlukan untuk mendukung mikrokontroler. Arduino Mega2560 adalah versi terbaru yang menggantikan versi Arduino Mega dengan model seperti terlihat pada gambar 1 .

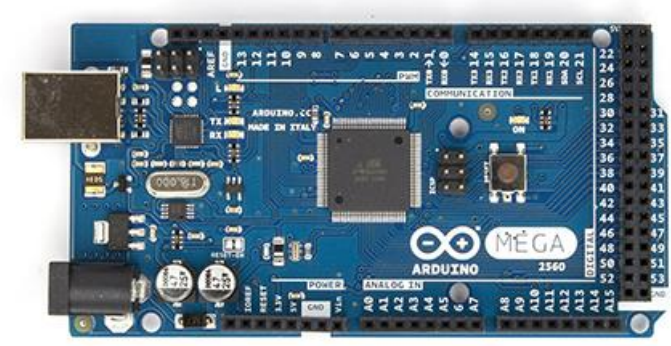

Gbr. 1 Modul Arduino Mega 2560

Arduino Mega 2560 memiliki sejumlah fasilitas untuk berkomunikasi dengan komputer, dengan Arduino lain, atau dengan mikrokontroler lainnya. Arduino ATmega328 menyediakan 4 hardware komunikasi serial UART TTL (5 Volt). Sebuah chip ATmega16U2 yang terdapat pada papan digunakan sebagai media komunikasi serial melalui USB dan muncul sebagai COM Port Virtual (pada Device komputer) untuk berkomunikasi dengan perangkat lunak pada komputer, untuk sistem operasi Windows masih tetap memerlukan file inf, tetapi untuk sistem operasi OS X dan Linux akan mengenali papan sebagai port COM secara otomatis. Perangkat lunak Arduino didalamnya serial monitor memungkinkan data tekstual sederhana dikirim ke dan dari papan Arduino. LED RX dan TX yang tersedia pada papan akan berkedip ketika data sedang dikirim atau diterima melalui chip USB-to-serial yang terhubung melalui USB komputer (tetapi tidak untuk komunikasi serial seperti pada pin 0 dan 1).[6]

\subsection{Penelitian Terkait \\ Adapun penelitian yang terkait dengan topik yang} diangkat oleh penulis adalah sebagai berikut :
1. Shyr-Kuen Chen, Tsair Kao, Chia-Tai Chan, ChihNing Huang, Chih-Yen Chiang, Chin-Yu Lai, Tse-Hua Tung, and Pi-Chung Wang. "A Reliable Transmission Protocol for ZigBee-Based Wireless Patient Monitoring". IEEE transactions on information technology in biomedicine, vol. 16, no. 1, january 2012. Penelitian ini membahas tentang sistem protokol berbasis ZigBee untuk melakukan pengiriman data pasien dimana pada sistem monitoring digunakan jaringan wimax dan internet.[7]

2. B.G.Sudharshan, S.C Prasanna Kumar, Shashiraj Yadav R V. "A Review Of Various Technologies And Transmission Modes For Design And Development Of A Transmission Enabled Glucometer". International Journal of Research in Engineering and Technology. Volume: 03 Issue: 06, June-2014. Penelitian ini membahas tentang perbandingan metode transmisi menggunakan GSM, Zigbee, Bluetooth, dan WiFi. Penelitian ini menyimpulkan bahwa penggunaan media transmisi bluetooth lebih murah dan lebih sederhana dibandingkan GSM, Zigbee, dan WiFi.[8]

3. Amil Ahmad Ilham, Elyas palantei, dan Santi. "Sistem Telemedis Interaktif untuk Penanganan Pasien Rawat jalan". Seminar Nasional Microwave Antena dan Propagasi Universitas Mercu Buana. Yogyakarta, 2014. Dihasilkan alat monitoring suhu tubuh dan denyut nadi pasien dengan menggunakan sensor suhu tubuh dan denyut nadi melalui jaringan LAN.[9]

Sedangkan pada penelitian ini, sistem monitoring yang dirancang lebih sederhana dikarenakan hanya menggunakan jaringan internet saja dan digunakan blueetooth sebagai media transmisi data yang sederhana dan difokuskan hanya pada pengukuran gula darah sehingga lebih ekonomis dibandingkan penelitian yang ada sebelumnya.

\section{METODE PENELITIAN}

Berikut akan diuraikan sistem pengolahan data gula darah pada glucometer dimana glucometer akan digunakan pada subjek (pasien) untuk mengukur kadar gula darah. Hasil pembacaan berupa nilai kadar gula darah $(\mathrm{mg} / \mathrm{dl})$ kemudian akan dikirim ke perangkat penerima yang terdapat pada pihak medis melalui jaringan telemedis. Adapun blok Diagram glucometer terlihat pada gambar 2.

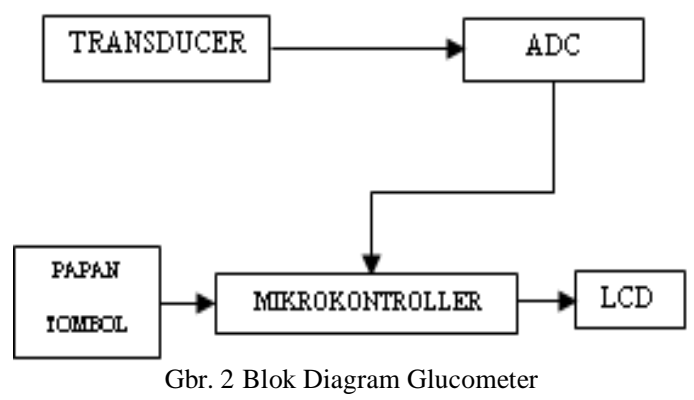

Prinsip kerja dari glucometer diuraikan sebagai berikut : 
e-ISSN : 2715-5064

Pada glucometer terdapat test strip yang berisi sampel darah serta berfungsi sebagai sensor pendeteksi gula darah. Sensor ini memiliki pendekatan enzimatik elektro yang menggunakan prinsip glukooksidase (GOD). Dengan adanya prinsip glukooksidase akan menyebabkan reaksi kimia antara glukosa dan oksigen sehingga meningkatkan $\mathrm{PH}$ darah yang menghasilkan asam glukonat dan $\mathrm{H}_{2} \mathrm{O}_{2}$. Ketika darah (glukosa $+\mathrm{O} 2$ ) diletakkan pada test strip maka terjadi reaksi kimia di dalamnya sehingga akan menghasilkan arus yang kecil pada konsentrasi gula darah tadi. Pada transducer, arus yang kecil diubah ke dalam bentuk tegangan menggunakan current to voltage converter [10], kemudian dikuatkan menggunakan amplifier sehingga tegangan yang dihasilkan berkisar 0-5 volt. Tegangan yang berupa besaran elektris atau analog tersebut masuk ke dalam Analog to Digital Converter (ADC) lalu diubah menjadi sinyal 8 bit. Sinyal keluaran ADC akan masuk ke mikrokontroller yang terintegrasi di dalam glucometer untuk diolah datanya. Hasil pengolahan data tersebut kemudian diumpankan ke LCD oleh mikrokontroller untuk ditampilkan hasilnya. Papan tombol pada glucometer merupakan tombol instruksi bagi mikrokontroller.

Secara khusus sistem transmisi data gula darah dari glucometer menuju handphone diperlihatkan pada gambar 3.

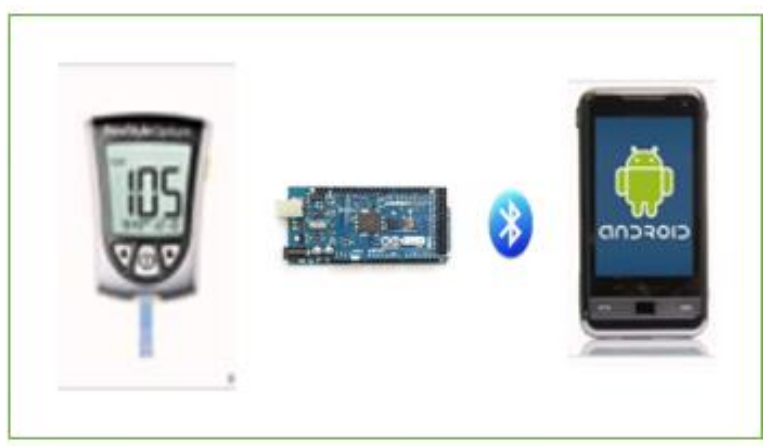

Gbr. 3 Sistem Transmisi Data Gula Darah

Adapun tahapan transmisi data gula darah dapat dijelaskan sebagai berikut.

1. Start

Ketika glucometer mulai dinyalakan maka akan muncul respon untuk memasukkan test strip gula darah seperti terlihat pada gambar 4. Lalu masukkan test strip dan lekatkan darah sampel ke atas test strip sehingga muncul angka pada layar LCD Glucometer.

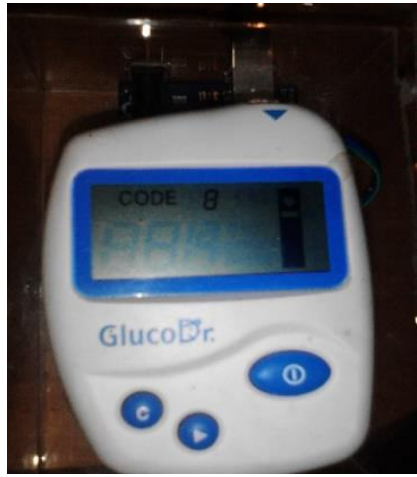

Gbr. 4 Tampilan Untuk Memasukkan Test Strip

2. Perancangan Port Glucometer ke Arduino dan Blueetooth

Tahap ini dilakukan inisialisasi sambungan antara port glucometer dengan port arduino.Pada LCD terdapat 7 port (Seg1-Seg7) sebagai tampilan seven segment dan 4 port sinyal Com (Com1-Com4). Output dari port-port pada LCD glucometer ini berupa sinyal analog yang selanjutnya disambungkan ke arduino. Seluruh port seven segment beserta port sinyal Com dihubungkan ke input analog arduino yakni mulai dari input analog 0 hingga input analog 10 (A0-A10). Sedangkan sisi positif baterai pada glucometer dihubungkan ke port Vec 3,3 volt dan sisi negatif baterai dihubungkan ke port GND pada arduino sebagai power supply. Secara umum diagram port LCD glucometer yang terhubung ke port arduino diperlihatkan pada gambar 5 .

Untuk sambungan port dari arduino ke bluetooth, Vcc 5 volt arduino dihubungkan ke Vcc pada bluetooth sedangkan GND arduino dihubungkan ke GND pada bluetooth. Demikian pula port TX1 arduino disambungkan ke port RX pada bluetooth, sedangkan port RX1 arduino dihubungkan ke port TX pada bluetooth sebagai sambungan untuk pengiriman dan penerimaan data gula darah. 
e-ISSN : 2715-5064

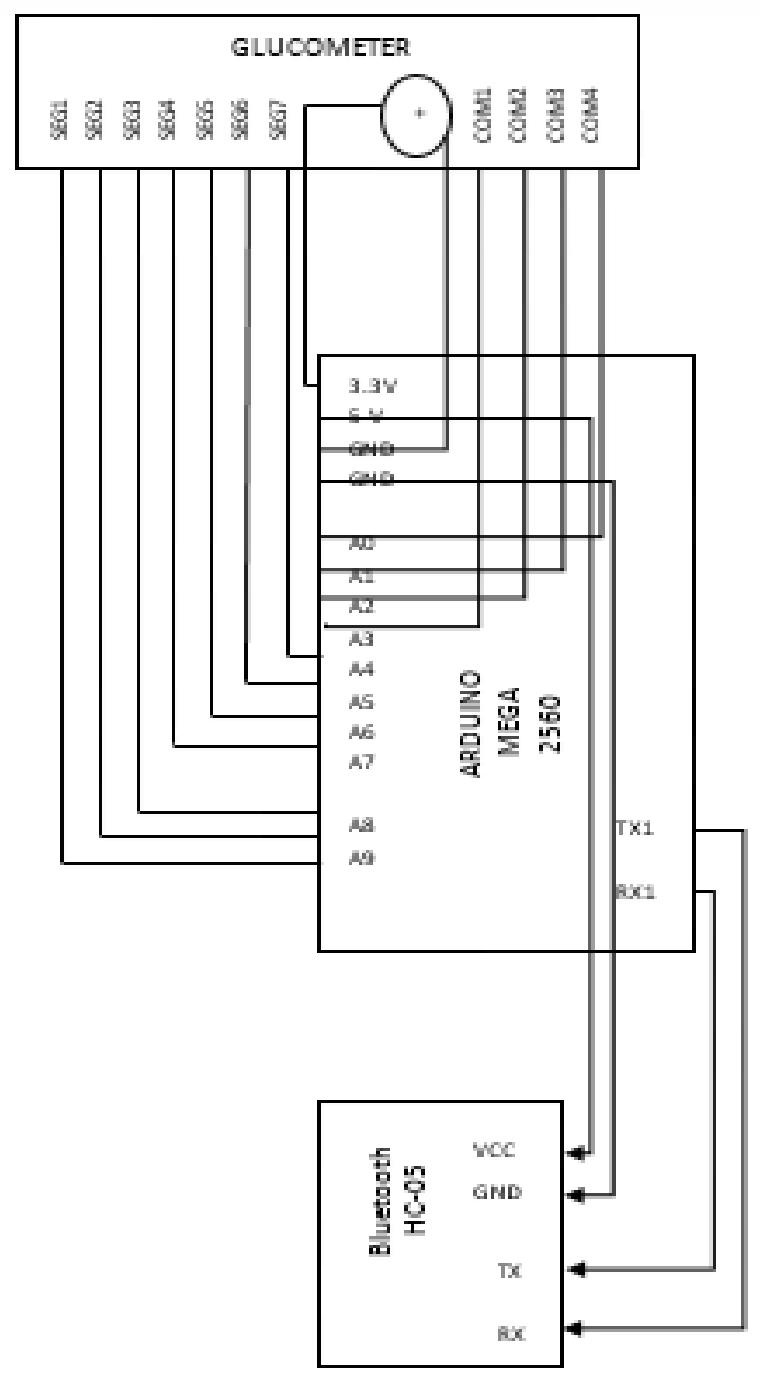

Gbr. 5 Rancangan Diagram Port Glucometer, Arduino dan Bluetooth

3. Pengaturan Program Arduino

Arduino memproses hasil pembacaan data gula darah yang muncul pada layar LCD Glucometer dengan mengatur program pada arduino.

4. Tampilan Data Pengukuran pada Layar Handphone

Selanjutnya data gula darah yang dikirim melalui bluetooth ditransmisikan ke handphone.Untuk tampilan pengiriman data pasien pada android.

\section{HASIL DAN PEMBAHASAN}

Setelah perancangan selesai maka dilakukanlah uji coba terhadap sistem transmisi data gula darah dengan melakukan pengamatan terhadap proses transmisi data tersebut selama 60, 90, dan 120 detik sebanyak $3 x$ percobaan dengan nilai gula darah yang terbaca pada glucometer adalah $86 \mathrm{mg} / \mathrm{dl}$ dan diperoleh hasil tampilan data pengukuran gula darah untuk percobaan I dengan waktu pengamatan 60 detik pada layar handphone. Untuk menghitung persentase nilai error dari pengamatan selama 60 detik diperoleh dengan membagikan antara banyaknya jumlah nilai error yg muncul dibagi dengan total nilai yang muncul. Sehingga diperoleh nilai real sebagai berikut :

$$
\text { error }=\frac{3}{20} \times 100 \%=15 \%
$$

Untuk pengamatan selama 60 detik diperoleh nilai error rata-rata sebesar $23,33 \%$. Nilai error untuk masing-masing percobaan dapat dilihat pada Tabel I.

TABEL I

HASIL PERCOBAAN UNTUK WAKTU PENGAMATAN 60 DETIK

\begin{tabular}{|c|c|}
\hline Jumlah Percobaan & Nilai Error \\
\hline Percobaan I & $15 \%$ \\
\hline Percobaan II & $30 \%$ \\
\hline Percobaan III & $25 \%$ \\
\hline Rata - rata & $\mathbf{2 3 , 3 3 \%}$ \\
\hline
\end{tabular}

Untuk hasil pengamatan selama 90 detik diperoleh nilai error sebagai berikut :

$$
\text { error }=\frac{5}{25} \times 100 \%=20 \%
$$

Untuk waktu pengamatan selama 90 detik diperoleh nilai error rata-rata sebesar $32 \%$. Nilai error untuk masingmasing percobaan dapat dilihat pada Tabel II.

TABEL II

HASIL PERCOBAAN UNTUK WAKTU PENGAMATAN 90 DETIK

\begin{tabular}{|c|c|}
\hline Jumlah Percobaan & Nilai Error \\
\hline Percobaan I & $20 \%$ \\
\hline Percobaan II & $40 \%$ \\
\hline Percobaan III & $36 \%$ \\
\hline Rata - rata & $\mathbf{3 2} \%$ \\
\hline
\end{tabular}

Sedangkan untuk hasil pengamatan selama 120 detik diperoleh nilai error sebagai berikut :

$$
\text { error }=\frac{11}{30} \times 100 \%=36,67 \%
$$

Untuk waktu pengamatan selama 120 detik diperoleh nilai error rata-rata sebesar $31,11 \%$. Nilai error untuk masingmasing percobaan dapat dilihat pada Tabel III.

TABEL III

HASIL PERCOBAAN UNTUK WAKTU PENGAMATAN 120 DETIK

\begin{tabular}{|c|c|}
\hline Jumlah Percobaan & Nilai Error \\
\hline Percobaan I & $36,67 \%$ \\
\hline Percobaan II & $26,67 \%$ \\
\hline Percobaan III & $30 \%$ \\
\hline Rata -rata & $\mathbf{3 1 , 1 1 \%}$ \\
\hline
\end{tabular}

Berdasarkan Hasil Pengamatan di atas terlihat bahwa terjadi ketidakstabilan nilai hasil pengukuran gula darah yang diterima oleh handphone. Sehingga dari rumus yang dijelaskan sebelumnya telah diperoleh nilai error hasil 
e-ISSN : 2715-5064

pengamatan secara keseluruhan seperti terlihat pada Tabel IV.

TABEL IV

NILAI ERROR HASIL SELURUH PENGAMATAN

\begin{tabular}{|c|c|}
\hline $\begin{array}{c}\text { Waktu Pengamatan } \\
\text { (detik) }\end{array}$ & $\begin{array}{c}\text { Nilai Error Rata-rata } \\
(\boldsymbol{\%})\end{array}$ \\
\hline 60 & 23,33 \\
\hline 90 & 32 \\
\hline 120 & 31,11 \\
\hline
\end{tabular}

Berdasarkan tabel dapat diketahui bahwa nilai hasil pengukuran yang terbaca pada layar handphone tidak konstan, namun telah dibuatkan aplikasi pada android untuk mengatasi hal tersebut. Program yang dibuat dengan sengaja dirancang untuk mengatasi nilai yang tidak stabil yang tampil pada handphone. Melalui program ini, nilai real yang terbaca di stop dengan tombol lalu dikirim ke server.

\section{KESIMPULAN}

\section{A. Kesimpulan}

Setelah melakukan uji coba dan analisa terhadap hasil pengukuran gula darah maka dapat disimpulkan sebagai berikut :

1. Untuk hasil pengamatan selama 60 detik diperoleh nilai error sebesar $23,33 \%$.

2. Untuk hasil pengamatan selama 90 detik diperoleh nilai error sebesar $32 \%$.

3. Untuk hasil pengamatan selama 120 detik diperoleh nilai error sebesar $31,11 \%$.

4. Terjadi ketidakstabilan hasil pengukuran gula darah yang ditransmisikan ke handphone sehingga nilai error untuk tiap waktu pengamatan pun tidak menentu. Untuk mengatasi hal ini maka dibuatlah program pada handphone android agar nilai real yang diterima dapat disimpan lalu dikirim ke server.

B. Saran

Perlu pengembangan lebih lanjut terkait penggunaan alat ukur gula darah (glucometer) yang digunakan dengan pengukuran kadar gula darah tanpa mengambil sampel darah pasien serta diperlukan sistem yang dapat mengirimkan data gula darah pasien secara otomatis ke server tanpa menggunakan handphone android.

\section{UCAPAN TERIMA KASIH}

Terima kasih penulis ucapkan kepada Bapak Elyas Palantei, ST., M.Eng., Phd. dan Ibu Dr. Eng. Ir. Dewiani, ST, MT. yang banyak memberikan masukan demi terselesaikannya penelitian ini. Tidak lupa pula ucapan terima kasih kepada rekan-rekan sejawat yang juga ikut membantu penyelesaian penelitian ini.

\section{DAFTAR PUSTAKA}

[1] A. Ahmad Ilham, E. Palantei, dan Santi, Pengembangan Tampilan Visual Data Medis Pada Jaringan Telemedis Interaktif. Program Studi Teknik Elektro, Konsentrasi Teknik Informatika, Fakultas Teknik Universitas Hasanuddin. Makassar, 2014.

[2] R. Tamridho, Rancang bangun Alat Pengukur Kadar Gula Darah. Universitas Indonesia. Depok, 2010.

[3] Poedjiadi, Anna, Dasar-dasar Biokimia. Jakarta : Universitas Indonesia Press. 1994.

[4] P. Indriyani dan H. Supriyatno, Senam Aerobik Terhadap Penurunan Kadar Gula Darah pada Penderita DM Tipe 2 di Wilayah Puskesmas Bukateja Purbalingga. Semarang. 2007.

[5] E. Susanti dan N. Candra, "Perancangan Wireless Starter Kendaraan Bermotor Memanfaatkan Bluetooth Berbasis Arduino," Sigma Teknika, vol.1, No.2 : 207-225, November 2018.

[6] Hendriono, "Mengenal Arduino Mega 2560". [online]. Tersedia http://www.hendriono.com/blog/post/mengenal-arduino-mega2560 [Diakses : 18 Desember 2015].

[7] Shyr-Kuen Chen, Tsair Kao, Chia-Tai Chan, Chih-Ning Huang, Chih-Yen Chiang, Chin-Yu Lai, Tse-Hua Tung, and Pi-Chung Wang, "A Reliable Transmission Protocol for ZigBee-Based Wireless Patient Monitoring", IEEE transactions on information technology in biomedicine, vol. 16, no. 1, January 2012.

[8] B.G.Sudharshan, S.C Prasanna Kumar, and Shashiraj Yadav R V, "A Review Of Various Technologies And Transmission Modes For Design And Development Of A Transmission Enabled Glucometer", International Journal of Research in Engineering and Technology, vol. 03 Issue: 06, June-2014.

[9] Amil A. Ilham, Elyas Palantei, dan Santi, Pengembangan Tampilan Visual Data Medis Pada Jaringan Telemedis Interaktif. Program Studi Teknik Informatika, Universitas Hasanuddin, Makassar. 2014.

[10] Miriam Garcia Yanez, "Glucose Meter Fundamentals and Design", Freescale Semiconductor Document, Number:AN4364. Application Note Rev. 1, 01/2013. 